\title{
Successful ERCP through an endoscopic ultrasound-guided gastrojejunostomy
}

A 68-year-old man with a history of primary sclerosing cholangitis and hilar cholangiocarcinoma had presented with biliary obstruction and had undergone endoscopic retrograde cholangiopancreatography (ERCP) with stricture dilation and main right/left intrahepatic duct stent placement (7-Fr×12-cm). Some months after diagnosis, the patient had developed gastric outlet obstruction due to proximal duodenal infiltration by the primary tumor, and a gastrojejunostomy with a $15 \times 10-\mathrm{mm}$ lumen-apposing metal stent (LAMS) had been successfully created using endoscopic ultrasound (EUS) guidance.

The patient was monitored clinically and 3 months after the gastrojejunostomy elevation of liver function test (LFT) levels was noted. It was decided to perform an ERCP, using a diagnostic esophagogastroduodenoscopy (EGD) scope through the gastrojejunostomy ( $\triangleright$ Video 1, Fig. 1).

The EGD scope was advanced into the gastric body. The previously placed LAMS was seen ( $\mathbf{F i g .} \mathbf{2} \mathbf{a}$ ), and the gastroscope was advanced through the LAMS into the afferent limb of the gastrojejunostomy. After a short distance, the previously placed stents and the major papilla were identified ( $\mathbf{F i g . 2}$ b). A snare was used to retrieve the stents. Then a sphincterotome preloaded with a 0.025 -inch guidewire was advanced. Given the approach to the papilla, the bile duct orifice was inverted, approximately at 5-o'clock. The common bile duct was successfully cannulated using the EGD scope (with no elevator, therefore). The guidewire was then advanced proximally into the right intrahepatic duct. Contrast was injected and the cholangiogram showed the hilar stricture ( $\mathbf{F i g . 2 c}$ ). Then the sphincterotome was carefully exchanged with the guidewire, keeping the position stable, and a $7-\mathrm{Fr} \times 15-\mathrm{cm}$ plastic stent was deployed across the stricture ( $\mathbf{F i g . 2 d}$ ). The sphincterotome, preloaded with the 0.025 -inch

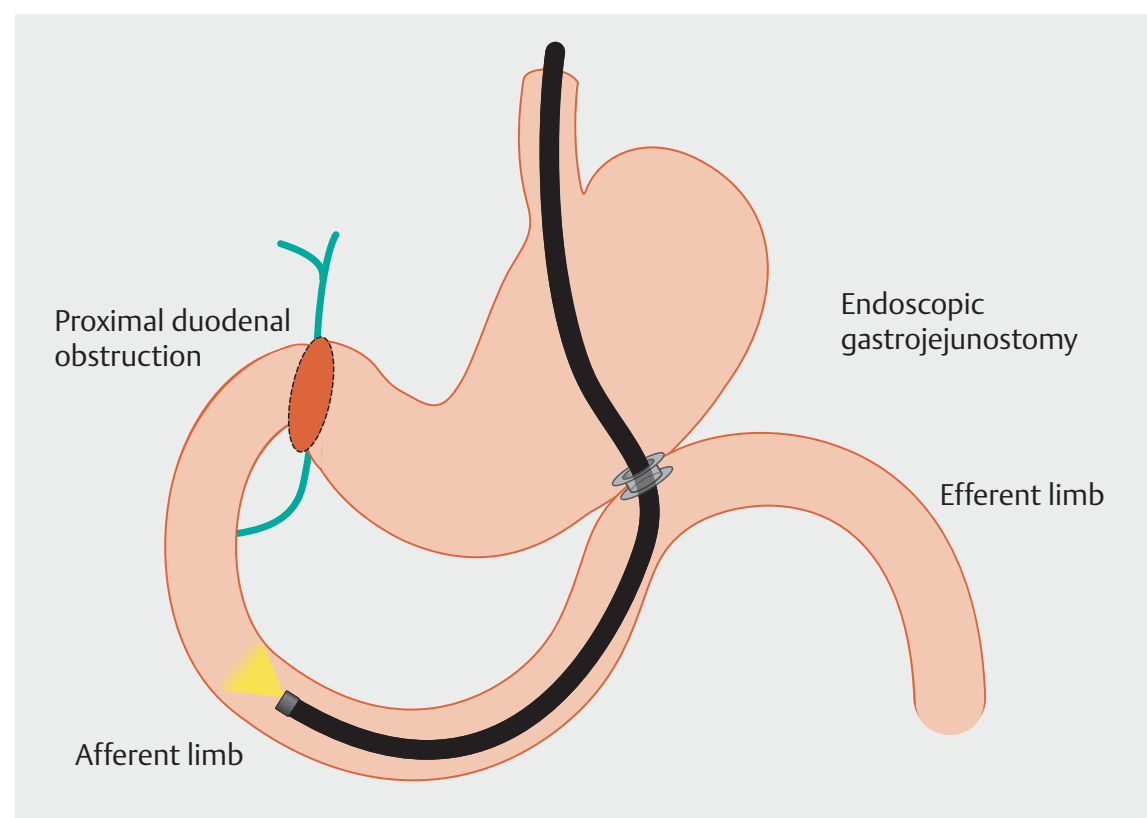

- Fig. 1 Endoscopic retrograde cholangiopancreatography (ERCP) through a gastrojejunostomy, using a standard scope: route through the gastrojejunostomy into the afferent limb and towards the papilla.

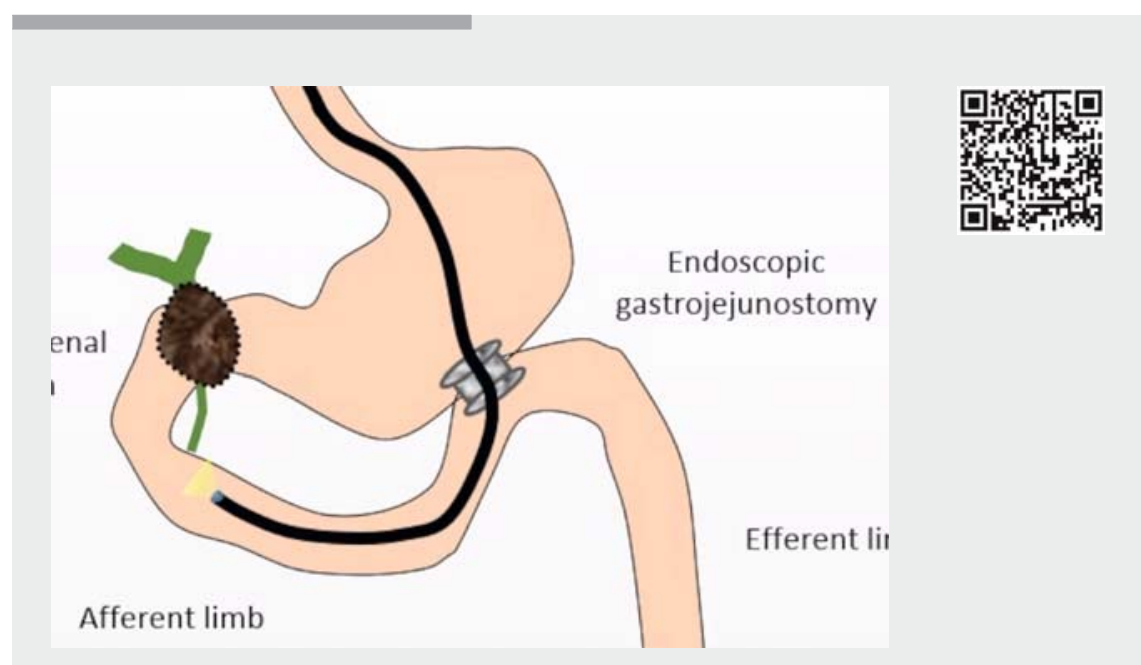

Video 1 Endoscopic retrograde cholangiopancreatography (ERCP) via the afferent limb of an endoscopic ultrasound-guided gastrojejunostomy. 

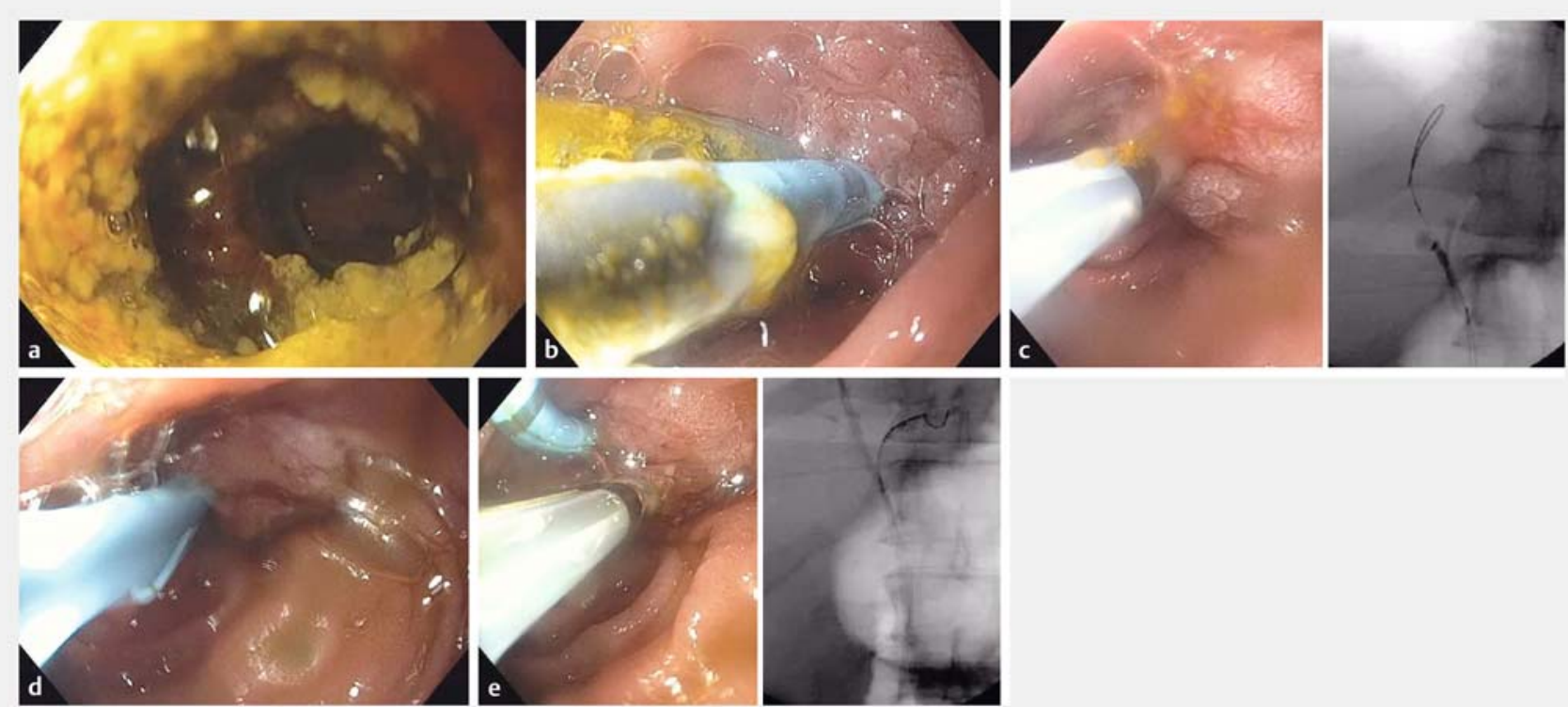

- Fig. 2 Endoscopic retrograde cholangiopancreatography (ERCP) through an EUS-guided gastrojejunostomy. a Endoscopic view of lumenapposing metal stent (LAMS) in the posterior wall of the gastric body before advancement through the gastrojejunostomy. $\mathbf{b}$ The major papilla and stents previously placed because of biliary obstruction. c Endoscopic and fluoroscopic view of common bile duct cannulation, using a sphincterotome preloaded with a 0.025 -inch guidewire. The right intrahepatic duct was selectively cannulated. $\mathbf{d}$ After exchange of the guidewire with the sphincterotome, a $7-\mathrm{Fr} \times 15-\mathrm{cm}$ plastic stent was deployed into the right intrahepatic duct. e The sphincterotome preloaded with the 0.025 -inch guidewire was advanced again and the left intrahepatic duct was selectively cannulated, and a second $7-\mathrm{Fr} \times 15-\mathrm{cm}$ plastic stent was placed.

guidewire, was used again to cannulate the common bile duct alongside the placed stent. The guidewire was then advanced into the left intrahepatic duct and exchanged with the sphincterotome ( $\triangleright$ Fig. 2 e). A second 7-Fr $\times 15-\mathrm{cm}$ plastic stent was deployed successfully. Maintenance of a stable position and adequate distance from the papilla were crucial to accomplish the procedure.

The procedure was well tolerated and the LFT results normalized. The patient has not developed signs of gastric outlet obstruction or of obstructive jaundice after 3 months of follow-up.

Malignant gastric outlet obstruction can be successfully treated with EUS-guided gastrojejunostomy, which is less invasive than surgery and is feasible [1]. However, when gastric outlet obstruction is treated with a duodenal self-expandable metal stent that covers the papilla, this makes ERCP challenging with only a $34 \%$ chance of success [2].

ERCP through the afferent limb of an EUS-guided gastrojejunostomy in patients with gastric outlet obstruction has not been previously reported. This approach is feasible, though possible only in patients with a proximal duodenal obstruction. The distance from the gastrojejunostomy through the afferent limb to the major papilla is short, allowing ERCP with a diagnostic EGD scope. Although performing ERCP with a gastroscope can be challenging due to the lack of an elevator, the procedure can be accomplished successfully.

\section{Endoscopy_UCTN_Code_TTT_1AS_2AG}

\section{Competing interests}

M. A. Khashab is a consultant for Boston Scientific.

\section{The Authors}

Olaya I. Brewer Gutierrez, Majidah Bukhari, Yen I. Chen, Omid Sanaei, Mouen A. Khashab Division of Gastroenterology and Hepatology, Johns Hopkins Medical Institutions, Baltimore, Maryland, United States

\section{Corresponding author}

\section{Mouen A. Khashab, MD}

Johns Hopkins Hospital, 1800 Orleans Street, Sheikh Zayed Tower, Baltimore, MD 21287, USA

Fax: +1-410-502-7010

mkhasha1@jhmi.edu

\section{References}

[1] Itoi T, Baron TH, Khashab MA et al. Technical review of endoscopic ultrasonographyguided gastroenterostomy in 2017. Dig Endosc 2017; 29: 495-502

[2] Khashab MA, Valeshabad AK, Leung W et al. Multicenter experience with performance of ERCP in patients with an indwelling duodenal stent. Endoscopy 2014; 46: 252-255

\section{Bibliography}

DOI https://doi.org/10.1055/s-0043-111711

Published online: 29.6.2017

Endoscopy 2017; 49: 921-922

(c) Georg Thieme Verlag KG

Stuttgart · New York

ISSN 0013-726X 